\title{
Report from the Executive Committee Meeting in Berlin, 22-23 March 2019
}

Richard Elwes, EMS Publicity Officer

Technische Universität Berlin is an important place in the current life of the EMS: it was the site of the 2016 European Congress, and is the home institution of the new EMS President Volker Mehrmann. (This is no coincidence, as Volker was also the Chair of the ECM's local organising committee.) It was to TU Berlin that the EMS Executive Committee returned in the spring.

The meeting was generously hosted by the International Association of Applied Mathematics and Mechanics (GAMM) and the German Mathematical Society (DMV), and on Friday evening Heike Faßbender and Friedrich Götze, respective Presidents of the two societies, welcomed the assembled company to Germany, and told us about them. Founded in 1890, the DMV can boast Georg Cantor, Felix Klein, David Hilbert and Hermann Minkowski among its former Presidents. With 4500 current members (including maths students, schoolteachers, and mathematicians in industry) the DMV is a large and very active society with many international connections and regular meetings, often jointly with other countries. It awards several prizes including the biennial Cantor Medal and (jointly with the IMU) the quadrennial Carl Friedrich Gauss Prize for Applications of Mathematics.

Meanwhile GAMM (the International Association of Applied Mathematics and Mechanics) was founded in 1922 by Richard von Mises and Ludwig Prandtl, with a stated purpose of promoting "scientific research in all branches of mechanics, mathematics and physics, which are among the foundations of engineering, primarily through the organization of scientific meetings." It now boasts over 1300 members, 17 Activity Groups, 6 Student Chapters, and an annual meeting of over 1200 participants.

\section{Officers' reports}

The meeting was opened by Volker Mehrmann, acting as Chair for the first time. He presented a report on his activities since the start of his Presidency in January. He also drew the committee's attention to FAIRmat, a proposal in which the EMS has participated regarding Mathematical Data for the European Open Science Cloud, based on the FAIR principles: Findability, Accessibility, Interoperability, and Reusability. For more details see www.opendreamkit.org/2019/01/29/FAIRmat/.

EMS Treasurer Mats Gyllenberg then presented his report on the society's income and expenditure for 2018. The society's finances remain healthy, with expenditure on scientific projects in line with the allocated budget. The committee approved his report and proposal to transfer funds into the EMS portfolio.
After Secretary Sjoerd Verduyn Lunel had delivered his report, the EMS' new Vice President Betül Tanbay led a discussion on the role of the Executive Committee members within the EMS. It was agreed that handbooks should be created for all EC posts, including the President, to make explicit the expectations of the roles and to help build institutional memory.

\section{Membership and scientific meetings}

The Executive Committee was pleased to approve a list of 68 new individual members and one new institutional member: The Department of Mathematics of the Institute for Mathematics, Astrophysics and Particle Physics of Radboud University. The EC discussed those members in arrears, whose membership may be terminated at the 2020 EMS Council meeting if they fail to respond to EMS correspondence. The EMS is also slowly accumulating individual lifetime members, following the introduction in 2018 of that system.

For an update on the 8th European Congress of Mathematics in Portorož, see the report from the Presidents' meeting on page 5. Looking ahead to 2024, the EMS has received two preliminary bids for the 9th ECM, both of which the committee agreed to invite to develop into full bids to be presented to the EMS Council in 2020.

This is a busy time for EMS-sponsored events, with 14 EMS supported Summer Schools planned over 2019. There was also discussion of broadening the range of meetings that occur under the EMS banner to include recurring thematic conferences.

\section{Standing committees and projects}

Stéphane Cordier, the Chair of the Applied Mathematics Committee in attendance as a guest, presented his report. For more details of the AMC's activities including ESSAM (EMS Summer Schools in Applied Mathematics), see its webpage: https://euro-math-soc.eu/committee/ applied-mathematics.

The committee then discussed reports from the committees on Developing Countries, Education, Publication and Electronic Dissemination, Raising Public Awareness of Mathematics, and Women in Mathematics.

The committee discussed a number of projects the EMS is involved in, including the European Digital Mathematics Library (http://www.eudml.org), the online Encyclopaedia of Mathematics (www.encyclopediaof math.org), EU-MATHS-IN (the European Service Network Of Mathematics For Industry And Innovation), and plans for a future Global Digital Mathematics Library. 


\section{Publicity and publishing}

The EMS Publicity Officer Richard Elwes presented his report, on publicity both on- and offline. The EMS's social media presence continues to grow, with over 4000 followers on Twitter and approaching 3000 on Facebook.

The President then presented a report on the future of the EMS Publishing House and its move to Berlin, with the successful establishment of a new limited company under German Law owned by the EMS. The committee welcomed the progress that has been made.

The EC discussed other matters relating to publications, including a report from the Editor-in-Chief of the EMS Newsletter Valentin Zagrebnov, the EMS's quarterly e-news (www.euro-math-soc.eu/e-news), and Zentralblatt (www.zbmath.org).

\section{Relations with funding organisations and political bodies}

The President reported on recent developments around Horizon 2020 and its successor framework, Horizon Europe. He reiterated the importance of our community speaking with one voice to enhance the prominence of mathematics in the political sphere. The President then gave an update on European Research Council, particularly a letter to encourage the mathematics community to submit proposals (this can be read in the latest e-news: www.euro-math-soc.eu/news/19/06/12/ems-e-news-31june-2019).

The next ESOF (European Open Science Forum) will be in 2020 in Trieste (overlapping with, and close to, the next ECM). It is expected that the committee for Raising Public Awareness of Mathematics will deliver a session there.

The President led a discussion on "Plan S", the initiative for open-access science publishing proposed by Science Europe. The EC expressed its thanks for the actions of the committee for Publishing and Electronic Dissemination, particularly the EMS's response to the open consultation on Plan S. This can be read at www.euro-math-soc. eu/news/19/02/8/feedback-ems-implementation-plan-s.

\section{Relations with mathematical organisations}

The President provided an update on the International Mathematical Union (of which the EMS is an adhering organisation) under the new Presidency of Carlos Kenig. The committee agreed to appoint Vice President Betül Tanbay as liaison officer with the IMU, with the aim of improving communication between the two bodies. There was a lively discussion about the appropriate roles of the ICM and ECM in the mathematical calendar. This is expected to continue at future meetings.

The committee discussed the EMS's joint work with other mathematical organisations, including ICIAM (the International Council for Industrial and Applied Mathematics), ECMI (European Consortium for Mathematics in Industry), the Bernoulli Society, CIMPA (the International Centre of Pure and Applied Mathematics), TICMI (Tbilisi International Centre of Mathematics and Informatics), the Banach Centre, the Abel Prize, and the Gordin Prize.

\section{Conclusion}

The committee expressed its thanks to the local organisers at TU Berlin and to Presidents Heike Faßbender (GAMM) and Friedrich Götze (DMV) for the excellent hospitality and organisation we have become used to in Berlin. However, in contrast to previous EC meetings, the assembled company did not then disperse, as the annual Meeting of Presidents of EMS Member Societies followed immediately (see below).

The next Executive Committee meeting will be 11-13 October in Yerevan (Armenia). 